Preface

\title{
At the Crossroads of Transfusion Medicine and Hemostasis
}

\author{
Hau C. Kwaan, MD, FRCP ${ }^{1}$ Glenn Ramsey, MD $^{2}$ \\ ${ }^{1}$ Division of Hematology/Oncology, Feinberg School of Medicine, \\ Northwestern University, Chicago, Illinois \\ 2 Department of Pathology, Feinberg School of Medicine, \\ Northwestern University, Chicago, Illinois \\ Semin Thromb Hemost 2016;42:93-94.
}

With increasing and widespread use of blood products in clinical practice, many adverse effects have been observed, although most of the risks involved are now better understood. Common adverse effects include transmission of infectious agents, hemolytic reactions, and circulatory issues such as overload and transfusion-related lung injury. Less well known are the adverse effects on hemostatic functions. There can be both thrombotic and bleeding complications, ranging from minor side effects to life-threatening complications. The significance of many of these adverse effects is often underrecognized. Thus, we are presenting in this issue of Seminars in Thrombosis $\mathcal{E}$ Hemostasis a series of articles from prominent authors addressing these issues, and providing the latest update on our current understanding of these adverse effects, as well as other important considerations related transfusion and hemostasis.

To begin with, Shah et $\mathrm{al}^{1}$ present information on the use of fresh frozen plasma (FFP) for coagulopathy in critically ill patients. They review the indications for FFP but also point out the current trend to limit its use due to its adverse effects and because of the availability of alternative blood products. This article is followed by Dubovoy and Engoren, ${ }^{2}$ who provide useful information on the effect of red blood cells (RBCs) on hemostasis. They point out that microvesicles derived from the transfused $\mathrm{RBC}$ preparation may also contribute to an increased thrombotic risk. They also discuss the rheologic characteristics of RBCs influencing blood viscosity and that alterations in RBCs in diseases may change blood viscosity leading to microthrombi formation. One of us (H.C.K.) had indeed observed such changes in a patient with autoimmune hemolytic anemia with a high cold agglutinin titer. When intravenous immunoglobulin was administered, an abrupt increase in RBC aggregation occurred, resulting to extensive livedo reticularis (as illustrated by the image on the cover).

Franchini and Lippi $^{3}$ then provide both molecular and epidemiologic basis for the differences in thrombosis and bleeding in the different $\mathrm{ABO}$ groups, with those persons with group $O$ having the lowest risk for thrombosis and perhaps

Address for correspondence Hau C. Kwaan, MD, Division of Hematology/Oncology, Feinberg School of Medicine, Northwestern University, Chicago, IL (e-mail: h-kwaan@northwestern. edu). the highest risk for bleeding. This is followed by a discussion of the risk of platelet transfusions by Schmidt et $\mathrm{al}^{4}{ }^{4}$ who delineate several mechanisms by which platelet transfusions can be thrombogenic, especially in the setting of trauma and sepsis.

Targeted replacement of individual clotting factors must also deserve careful consideration of their adverse effects. Recombinant activated factor VII was first approved by the Food and Drug Administration specifically for bleeding control in patients with inhibitors of factor VIII and factor IX. However, it has been employed off-label in many other bleeding disorders. The associated increased risk of thrombosis is underrecognized. Goodnough and Levy ${ }^{5}$ review the mixed results of clinical trials to date. Next, a thorough review of the management of von Willebrand disease by Curnow et $\mathrm{al}^{6}$ provides important therapeutic guidelines on therapy using various blood products.

Human fibrinogen has recently been approved for use by regulatory agencies. Spahn et $\mathrm{al}^{7}$ discuss the evaluation of fibrinogen levels, emphasizing the whole blood testing methods of thromboelastography and thromboelastometry. They review published protocols for fibrinogen replenishment in various perioperative settings.

Our concluding set of reviews provides hemostatic perspectives in several recently evolving areas of transfusion therapy. Gando and Hayakawa ${ }^{8}$ discuss the complex hemostatic derangements in trauma and massive transfusion, highlighting disseminated intravascular coagulation, fibrinolysis, and the state of current research to correct these problems. Paparella and Whitlock ${ }^{9}$ review the underappreciated adverse effects of transfusing blood salvaged intraoperatively. This modality is widely employed to reduce allogeneic transfusions in cardiac surgery but can also induce coagulopathy and inflammation. Finally, Ramsey ${ }^{10}$ discusses pathogen-inactivated plasma and platelets. These blood products reduce the continuing risk of transfusion-transmitted infections, but with the tradeoff of reduced plasma
Copyright $\odot 2016$ by Thieme Medical Publishers, Inc., 333 Seventh Avenue, New York, NY 10001, USA. Tel: +1(212) 584-4662.
DOI http://dx.doi.org/ 10.1055/s-0035-1571266. ISSN 0094-6176.
Transfusion Medicine and

Hemostasis; Guest Editors: Glenn

Ramsey, MD, and Hau C. Kwaan, MD. 
clotting factor contents and lower platelet count responses, compared with untreated products.

The development of different blood problems and the consequences of associated adverse effects are better understood today. Thus, we believe these articles can give our readers updated information on the risk of these products, especially relative to issues of thrombosis and bleeding. We hope that our readers will enjoy reading them as much as we did assembling them.

\section{References}

1 Shah A, McKechnie S, Stanworth S. Use of plasma for acquired coagulation factor deficiencies in critical care. Semin Thromb Hemost 2016;42(2):95-101

2 Dubovoy T, Engoren M. Thrombotic risks in red blood cell transfusions. Semin Thromb Hemost 2016;42(2):102-111
3 Franchini M, Lippi G. Relative risks of thrombosis and bleeding in different ABO blood groups. Semin Thromb Hemost 2016;42(2): 112-117

4 Schmidt AE, Refaai MA, Blumberg N. Platelet transfusion and thrombosis: more questions than answers. Semin Thromb Hemost 2016;42(2):118-124

5 Goodnough LT, Levy JH. The judicious use of recombinant factor VIIa. Semin Thromb Hemost 2016;42(2):125-132

6 Curnow J, Pasalic L, Favaloro EJ. Treatment of von Willebrand disease. Semin Thromb Hemost 2016;42(2):133-146

7 Spahn DR, Spahn GH, Stein P. Indications and risks of fibrinogen in surgery and trauma. Semin Thromb Hemost 2016;42(2):147-154

8 Gando S, Hayakawa M. Pathophysiology of trauma-induced coagulopathy and management of critical bleeding requiring massive transfusion. Semin Thromb Hemost 2016;42(2):155-165

9 Paparella D, Whitlock R. Safety of salvaged blood and risk of coagulopathy in cardiac surgery. Semin Thromb Hemost 2016; 42(2):166-171

10 Ramsey G. The hemostatic efficacy of pathogen-inactivated blood components. Semin Thromb Hemost 2016;42(2):172-182 